\title{
TO CORRELATE THE INCIDENCE OF CONGENITAL ANOMALIES ON ANTENATAL SCAN AND THOSE DETECTED IN POSTNATAL PERIOD IN KRISHNA INSTITUTE OF MEDICAL SCIENCES, KARAD
}

\author{
Suryakant Yeshwant Ingale1, Shreya Sharat Menon²
}

${ }^{1}$ Associate Professor, Department of Paediatrics, Krishna Institute of Medical Sciences.

${ }^{2}$ Resident, Department of Paediatrics, Krishna Institute of Medical Sciences.

\section{ABSTRACT}

\section{BACKGROUND}

Objective - To determine the number of congenital anomalies which were detected antenatally in antenatal scans and those detected during the postnatal period in Krishna Institute of Medical Sciences, Karad.

\section{MATERIALS AND METHODS}

A prospective cross sectional study was done for 1 year. All normal and LSCS deliveries were included in the study. All pregnant registered women were screened for congenital anomalies at around 20 weeks of gestation. Postnatally, all babies with the risk of congenital anomalies detected on the antenatal scan and those with normal antenatal scan but definite/suspected congenital anomalies at birth were evaluated further.

\section{RESULTS}

From a total of 3200 registered pregnant cases which were antenatally scanned,

- Number of congenital anomalies detected was 134.

- Number of pregnancies terminated due to congenital anomalies which were incompatible with life was 40.

- Babies with normal antenatal scans but postnatal defects were 29.

\section{CONCLUSION}

For the detection of foetal anomalies and well-being, antenatal scan should be mandatory in all pregnant women irrespective of outcome of the pregnancy. Early assessment of foetal condition would help us prepare in advance for the anticipated outcome and transfer the baby to the higher centre if necessary or option of MTP can be offered in case of poor prognosis.

\section{KEYWORDS}

Congenital Anomaly, Antenatal, Postnatal.

HOW TO CITE THIS ARTICLE: Ingale SY, Menon SS. To correlate the incidence of congenital anomalies on antenatal scan and those detected in postnatal period in Krishna Institute of Medical Sciences, Karad. J. Evolution Med. Dent. Sci. 2017;6(5):395-397, DOI: $10.14260 /$ Jemds/2017/88

\section{BACKGROUND}

The incidence of congenital anomalies has increased due to the greater awareness among people, lately. It has become mandatory for pregnant women to undergo at least 3 ANC scans for assessing the gestational age, congenital anomalies, foetoplacental well-being. The incidence of congenital anomaly being $9 \%$ with perinatal death and $2 \%$ associated with major defect, the USG scan has gained more importance in detecting foetal anomalies.

The 18-20 week foetal anomaly scan is considered watershed in most pregnancies because for the majority of women it will be the last time they will be scanned before they deliver.

The scans provide the clinicians with better information because by now the babies were better developed and the functioning of various organs could be assessed.

Financial or Other, Competing Interest: None.

Submission 16-11-2016, Peer Review 04-01-2017,

Acceptance 10-01-2017, Published 16-01-2017.

Corresponding Author:

Dr. Shreya Sharat Menon,

Room No. 30, IHR Hostel,

Krishna Institute of Medical Sciences,

Malkapur-415110,

Satara.

E-mail: shremenon@yahoo.com

DOI: $10.14260 /$ jemds $/ 2017 / 88$

\section{(c) $(1)$}

Many times, just a marker detected by sonography was further evaluated by amniocentesis.

\section{Benefits Obtained}

- It opened an option for MTP, in case of poor prognosis or incompatibility with life.

- It helps the clinicians to prepare for the anticipated outcome.

- It helps psychologically prepare the parents regarding the outcome.

- Preparedness for the immediate reversal of the anomaly improves the prognosis.

\section{MATERIALS AND METHODS}

- Around 3200 registered women over 1 year with their antenatal scans were considered.

- Babies born by both NVD and LSCS were clinically scanned for any anomalies.

- All the babies with the risk for anomaly either detected on ANC scan antenatally or those with normal ANC scan but definite/suspected anomaly at birth were evaluated further.

\section{RESULTS}

From total of 3200 registered ANC scans obtained,

- Congenital anomalies were detected on ANC scan were 134 
- Pregnancies terminated due to fatal outcome or poor prognosis were 40 , of which

29 were due to anencephaly and congenital hydrocephalus.

6 congenital CVS malformations.

5 were detected with miscellaneous anomalies.

Babies with normal antenatal scan but defects found postnatally were 29 .

Congenital Anomalies on Antenatal Scan and Terminated were as follows:

\begin{tabular}{|c|c|c|}
\hline & CNS Anomalies & No. of Cases \\
\hline 1 & Anencephaly & 19 \\
\hline 2 & Congenital hydrocephalus & 10 \\
\hline & CVS Anomalies & \\
\hline 1 & TGA & 2 \\
\hline 2 & Truncus Arteriosus & 1 \\
\hline 3 & TAPVC & 1 \\
\hline 4 & TOF & 1 \\
\hline 5 & Single left ventricle & 1 \\
\hline & Miscellaneous Anomalies & \\
\hline 1 & Meningomyloceole & 3 \\
\hline 2 & Renal agenesis & 1 \\
\hline 3 & Diaphragmatic hernia & 1 \\
\hline
\end{tabular}

Congenital Anomalies were as follows on Antenatal Scan and Confirmed Postnatally

\begin{tabular}{|c|c|c|}
\hline & CNS Anomalies & No. of Cases \\
\hline 3 & Meningocoele and Meningomyelocoele & 11 \\
\hline 4 & Spina bifida & 3 \\
\hline 5 & Syringomyelia & 1 \\
\hline 6 & Corpus callosum agenesis & 1 \\
\hline 7 & Arnold Chiari malformation & 1 \\
\hline 8 & Diastematomyelia & 1 \\
\hline
\end{tabular}

\begin{tabular}{|c|c|c|}
\hline & CVS Anomalies $\mathbf{1}$ & No. of Cases \\
\hline 1 & ASD & 3 \\
\hline 2 & VSD & 3 \\
\hline 4 & TOF & 1 \\
\hline
\end{tabular}

\begin{tabular}{|l|c|c|}
\hline & Renal Anomalies & No. of Cases \\
\hline 1 & PUJ obstruction & 12 \\
\hline 2 & Multicystic kidney disease & 3 \\
\hline 3 & Hydronephrosis & 5 \\
\hline
\end{tabular}

\begin{tabular}{|l|c|c|}
\hline & GIT Anomalies & No. of Cases \\
\hline 1 & Abdominal cyst & 2 \\
\hline 2 & Duodenal atresia & 1 \\
\hline 4 & Gastroschisis & 1 \\
\hline 5 & Subcapsular haematoma of the liver & 1 \\
\hline
\end{tabular}

\begin{tabular}{|c|c|c|}
\hline & Musculoskeletal Anomalies & No. of Cases \\
\hline 1 & Single umbilical artery & 4 \\
\hline 2 & TAPVC & 2 \\
\hline 3 & Cleft palate & 2 \\
\hline 4 & Situs inversus & 1 \\
\hline 6 & Absent radius & 1 \\
\hline
\end{tabular}

Congenital Anomalies Obtained Postnatally with Normal ANC Scan

Total 54 babies had congenital anomalies detected postnatally with normal antenatal scans, which are as follows:

\begin{tabular}{|c|c|c|}
\hline & CNS Anomalies & No. of Cases \\
\hline 1 & Spina Bifida & 2 \\
\hline 2 & $\begin{array}{c}\text { Syringomyelia with } \\
\text { Lipomyelomeningocoele }\end{array}$ & 1 \\
\hline 3 & Microcephaly & 1 \\
\hline 4 & Hydrocephalus & 1 \\
\hline 5 & Sacral sinus & 1 \\
\hline
\end{tabular}

\begin{tabular}{|c|c|c|}
\hline & CVS Anomalies & No. of Cases \\
\hline 1 & ASD & 8 \\
\hline 2 & VSD & 3 \\
\hline 3 & TOF & 1 \\
\hline 4 & TAPVC & 1 \\
\hline 5 & Dextrocardia & 1 \\
\hline 6 & Dilated left ventricle & 1 \\
\hline 7 & PDA & 1 \\
\hline 8 & TGA & 1 \\
\hline
\end{tabular}

\begin{tabular}{|c|c|c|}
\hline & Renal Anomalies & No. of Cases \\
\hline 1 & PUJ obstruction & 5 \\
\hline 2 & Hydronephrosis & 2 \\
\hline 3 & Vesicovaginal fistula & 1 \\
\hline
\end{tabular}

\begin{tabular}{|c|c|c|}
\hline & GIT Anomalies & No. of Cases \\
\hline 1 & Gastroschisis & 1 \\
\hline 2 & Imperforated anus & 1 \\
\hline 3 & Ileocecal atresia & 1 \\
\hline 4 & Tracheoesophageal fistula & 1 \\
\hline
\end{tabular}

\begin{tabular}{|c|c|c|}
\hline & Musculoskeletal /Other Anomalies ${ }^{2,3}$ & No. of Cases \\
\hline 1 & Congenital laryngomalacia & 4 \\
\hline 2 & CTEV & 3 \\
\hline 3 & Single umbilical artery & 2 \\
\hline 4 & Cleft lip and Cleft palate & 2 \\
\hline 5 & DOMS & 1 \\
\hline 6 & Hypoplastic right sternocleidomastoid & 1 \\
\hline 7 & Imperforate anus with rectovaginal fistula & 1 \\
\hline 8 & Upper limb phocomelia with radial & 1 \\
\hline 9 & deformity & 1 \\
\hline 10 & Syndactyly of right foot & 1 \\
\hline 11 & Collodion baby & 1 \\
\hline 12 & Right eye retinal detachment & 1 \\
\hline
\end{tabular}

\section{DISCUSSION}

Congenital anomalies are important cause of still birth and infant mortality. The incidence of congenital anomalies is on the rise due to advanced diagnostic techniques. In our study, we considered 3200 registered pregnant cases, which were antenatally scanned. The total congenital anomalies detected antenatally and postnatally with normal antenatal scans were 149. The number of cases detected on antenatal scans were 134. The number of pregnancies terminated were 40 . Anencephaly and congenital hydrocephalus (70 \%) being the most common cause of termination followed by CVS anomalies (17\%).

Like the previous ICMR studies, (4) the maximum congenital anomalies detected antenatally were CNS anomalies (54\%) and those detected postnatally with normal antenatal scans 
were musculoskeletal in nature. In our hospital, insignificant amount of stillbirths were due to congenital anomalies as most of the pregnancies with poor outcome were terminated. Previous studies have reported male preponderance amongst congenitally malformed babies. Our findings were in accordance with this. Previous data(4),(5) shows an increase in the incidence of anomalies in babies born to consanguineous parent, $12 \%$ of the malformed babies had history of consanguinity. According to ICMR et al,(5) it has shown statistical significance with respect to age of the mother, above 30 years of age, a higher risk producing malformed babies ,which was insignificant in our study. Previous study(4),(5) has shown increased incidence with gravida 4 or more which was not consistent with our finding. There was an increased incidence of anomalies in the mother associated with hydramnios, eclampsia, uteroplacental insufficiency, previous history of abortion, premature rupture of membranes, toxaemia of pregnancy.(6)

The aim of the study to improve the measures for antenatal care by detecting and preventing anomalies whenever possible, as well as to improve the postnatal outcome of the babies born with anomalies. It also encourages us to keep the window of suspicion open in babies with normal scan. It also opens the horizon for intrauterine surgical correction.

\section{CONCLUSION}

Out of total of 3200 deliveries, number of congenital anomalies detected were 134 on antenatal scan, number of pregnancies terminated due to congenital anomalies which were not compatible with life were 40 . The commonest system involved being craniospinal system (70\%). The second most common being CVS anomaly (17\%).

Percentage of babies detected with CNS anomalies on ANC scan were $54 \%$ of the total anomalies detected antenatally. Percentage of babies detected with renal anomalies on ANC scan were $15 \%$ of the total anomalies detected antenatally. Percentage of babies detected with musculoskeletal anomalies and other miscellaneous anomalies on ANC scan were $8.1 \%$ of total anomalies detected antenatally. Percentage of babies detected with GIT anomalies detected on ANC scan were $4.4 \%$ of total anomalies detected antenatally.
Percentage of babies detected with musculoskeletal and miscellaneous anomalies postnatally with normal antenatal scans were $35 \%$. Percentage of babies detected with CVS anomalies postnatally with normal antenatal scans were $31 \%$. Percentage of babies detected with renal anomalies postnatally with normal antenatal scans were $14 \%$. Percentage of babies detected with CNS anomalies postnatally with normal antenatal scans was $11 \%$. Percentage of babies detected with GIT anomalies postnatally with normal antenatal scans were $7.4 \%$.

In $12 \%$ cases, history of consanguinity was present. Majority of the mothers were under 30 years of age, $46 \%$ were primigravida. In $32 \%$ of cases, congenital anomalies were detected before 28 weeks. There were increased anomalies in mothers associated with hydramnios, eclampsia, uteroplacental insufficiency, previous history of abortion, premature rupture of membranes and toxaemia of pregnancy.

\section{REFERENCES}

[1] Friedberg MK, Silverman NH, Moon-Grady AJ, et al. Prenatal detection of congenital heart disease. The Journal of Pediatrics 2009;155(1):26-31.

[2] Hoffman JI. Incidence of congenital heart disease: I. Postnatal incidence. Pediatr Cardiol 1995;16(3):103-13.

[3] Alladi A, Agarwala S, Gupta AK, et al. Postnatal outcome and natural history of antenatally-detected hydronephrosis. Pediatric surgery international 2000;16(8):569-72.

[4] Sarkar S, Patra C, Dasgupta MK, et al. Prevalence of congenital anomalies in neonates and associated risk factors in a tertiary care hospital in Eastern India. Journal of Clinical Neonatology 2013;2(3):131-4.

[5] Taksande A, Vilhekar K, Chaturvedi P, et al. Congenital malformations at birth in central India: a rural medical college hospital based data. Indian Journal of Human Genetics 2010;16(3):159-63.

[6] Chung CS, Myrianthopoulos NC. Factors affecting risks of congenital malformations. I. Analysis of epidemiologic factors in congenital malformations. Report from the collaborative perinatal project. Birth defects original article series 1975;11(10):1-22. 